\title{
Contribuições da Psicologia à educação: a crítica social de Dante Moreira Leite
}

\section{Contributions of Psychology to education: Dante Moreira Leite's social critique}

\section{Contribuciones de la Psicología para la educación: la crítica social de Dante Moreira Leite}

\author{
Maria Amélia Güllnitz Zampronha* \\ Universidade Federal de Goiás - UFG, Goiânia, Goiás, Brasil
}

\section{Odair Sass**}

Pontifícia Universidade Católica de São Paulo - PUC-SP, São Paulo, São Paulo, Brasil

\begin{abstract}
RESUMO
Discute-se, aqui, as contribuições da Psicologia, elaborada por Dante Moreira Leite, importante intelectual e psicólogo brasileiro, para a educação. O objetivo é analisar a crítica social realizada pelo pesquisador, quanto aos seus potenciais e limites, relacionando-a com as principais conclusões da teoria crítica da sociedade, conforme os autores da primeira geração. Constata-se que Dante debate problemas fundamentais da educação nacional, com destaque para seus estudos acerca dos conceitos de ideologia e preconceito, evidenciando que as manifestações de tais conceitos são psicológicas, mas as origens são sociais. Dante elaborou, então, proposições com o intuito de motivar o aluno, mantendo-o na escola e promovendo o seu aprendizado, de melhor preparar o professor, bem como para propugnar medidas pedagógicas, até hoje em discussão. No entanto, nota-se que suas proposições se voltam mais para a adaptação à ordem social vigente do que à crítica dessa ordem.
\end{abstract}

Palavras-chave: Dante Moreira Leite, psicologia, educação, ideologia, preconceito.

\section{ABSTRACT}

Here we discuss the contributions of Psychology to education, as formulated by Dante Moreira Leite, an important Brazilian intellectual and psychologist. Our objective is to analyse the social critique elaborated by this researcher, regarding its potentials and limits, relating it to the main conclusions of critical theory of society, as stablished by the authors of the first generation. Although Dante discusses fundamental problems of national education, here we highlight his studies regarding ideology and prejudice, whose manifestations are psychological, but origins are social. The author makes propositions with the intention of motivating the students, keeping them in school and promoting their apprenticeship, preparing the teacher, also advocating pedagogical measures that are until this day under discussion. 
However, it is noted that his propositions relate more to adaptation to the current social order than to the criticism of that order.

Keywords: Dante Moreira Leite, psychology, education, ideology, prejudice.

\section{RESUMEN}

Se discute, aquí, las contribuciones de la Psicología para la educación, conforme elaborada por Dante Moreira Leite, importante intelectual y psicólogo brasileño. El objetivo es analizar la crítica social elaborada por el investigador, en cuanto a sus potenciales y límites, relacionándola con las principales conclusiones de la teoría crítica de la sociedad, consonante con los autores de la primera generación. Se constata que Dante debate problemas fundamentales de la educación nacional, con destaque para sus estudios acerca de la ideología y el prejuicio, siendo que sus manifestaciones son psicológicas, pero sus orígenes son sociales. Elabora, entonces, proposiciones con el propósito de motivar al alumno, manteniéndolo en la escuela y promoviendo su aprendizaje, la preparación del profesor, así como propugnar medidas pedagógicas, hasta hoy en discusión. Sin embargo, se nota que sus proposiciones se vuelven más a la adaptación al orden social vigente que a la crítica de ese orden.

Palabra-clave: Dante Moreira Leite, psicología, educación, ideologia, prejuicio.

\section{I ntrodução}

O presente artigo delimita e apresenta um dos aspectos estudados por Zampronha (2017) com o objetivo de analisar como Dante Moreira Leite (1927-1976), um intelectual de relevante atuação na história da Psicologia brasileira, desenvolveu os conceitos de ideologia e preconceito ao longo de sua obra. Este artigo detém-se sobre as contribuições do conhecimento produzido pelo pesquisador para a educação, tomando dois elementos em consideração. Em primeiro lugar, a educação, um dos temas mais discutidos por ele, representa um de seus aportes mais significativos tanto para a Educação quanto para a Psicologia. O segundo elemento diz respeito à atualidade dos problemas educacionais por ele estudados, à medida que muitos deles continuam sem solução e permanecem em debate, com destaque para as suas pesquisas sobre preconceito e valores morais em livros didáticos infantis (Leite, 2008a, 2008b). Pretende-se, então, responder à pergunta: como e em que termos o intelectual formula a crítica social em suas pesquisas educacionais em face dos problemas próprios da sociedade, que interferem na educação brasileira? Portanto, o objetivo é discutir a crítica social por ele desenvolvida, destacando os potenciais e limites dessa crítica, relacionando-a àquela elaborada pelos autores da primeira geração da teoria crítica da sociedade, quais sejam, Max Horkheimer (18951973), Herbert Marcuse (1898-1979) e Theodor W. Adorno (19031969). 
Dante Moreira Leite foi pesquisador, professor e tradutor, com relevante atuação institucional e política, especialmente entre os anos 1950 e 1976. Realizou pesquisas concernentes a um amplo temário ${ }^{1}$, participou ativamente da criação do curso de Psicologia da Universidade de São Paulo (USP) e da regulamentação da profissão de psicólogo e defendeu a necessidade da criação de um código de ética da profissão. Por conta das características de produtor e divulgador de conhecimento e por sua atuação política, o pesquisador é, aqui, considerado um intelectual, que pode ser entendido como um produtor de conhecimento preocupado com o processo histórico e a crítica social (Baran, 1961).

Apesar de sua relevância, o autor é pouco estudado nos cursos de graduação em Psicologia e, provavelmente, em decorrência disso, sua obra não é apresentada com freqüência em pesquisas das áreas de Psicologia e da Educação. A história da Psicologia nos cursos de graduação geralmente não contempla a história nacional e as obras dos psicólogos fundadores da ciência no país não costumam ser estudadas; conseqüentemente, constituem tema ou referência pouco encontrados nas pesquisas acadêmicas da área, ainda que as obras de Dante tenham sido reeditadas há poucos anos, por uma editora universitária brasileira e seu acervo esteja disponível na Universidade de São Paulo. Esse relativo desconhecimento reitera a relevância de pesquisas e publicações concernentes à sua atuação e à sua obra. Assim, retomar suas contribuições científicas e políticas e homenagear sua memória tornam-se também objetivos deste artigo.

\section{Formação, Trajetória Institucional, Atuação Política e Pesquisas}

Nesse item, apresentam-se a formação acadêmica de Dante Moreira Leite, as instituições pelas quais passou e suas principais pesquisas. Tanto a biografia quanto a bibliografia do autor podem ser encontradas em Schmidt e Neves (2002) e em Zampronha (2017).

Dante cursou Filosofia, de 1947 a 1950, na então Faculdade de Filosofia, Ciências e Letras da Universidade de São Paulo (FFCL-USP). De 1950 em diante, dedicou-se ao ensino secundário no Colégio Mackenzie e no Colégio Paulistano, onde ministrou aulas de Filosofia e Psicologia, ao mesmo tempo que ao ensino universitário na USP e na Faculdade de Filosofia, Ciências e Letras (FFLC) de Araraquara ${ }^{2}$ (Schmidt \& Neves, 2002); à tradução do inglês para o português de importantes obras de Psicologia, Sociologia, Educação e Metodologia de pesquisa social ${ }^{3}$; à pesquisa científica e à regulamentação do curso de Psicologia e da profissão de psicólogo.

Durante a graduação, sua maior influência na área de Psicologia foi Annita de Castilho e Marcondes Cabral, sua orientadora de tese de 
doutoramento e de quem foi assistente, na cadeira de Psicologia da FFCL-USP, até 1958. Nesse período, ministrou as disciplinas de Psicologia Diferencial, Introdução à Psicologia, Psicologia da Personalidade e Problemas Teóricos de Psicologia (Leite, 1973). Com a tese intitulada O Caráter Nacional Brasileiro: Descrição das características psicológicas do brasileiro através de ideologias e de estereótipos, obteve o título de doutor em Psicologia, em 1954. Em seguida, recebeu uma bolsa de estudos para passar o ano letivo de 1955 a 1956 na Universidade do Kansas, Estados Unidos.

Após seu retorno, em 1957, assumiu a Divisão de Estudos e Pesquisas Educacionais (DEPE), uma das seções de pesquisa do Centro Regional de Pesquisas Educacionais do Sudeste (CRPE), instituição subordinada ao Instituto Nacional de Estudos Pedagógicos (INEP), a convite de Fernando de Azevedo, então, diretor da instituição. Exerceu essa função até 1959. As pesquisas realizadas pelo CRPE visavam conhecer as necessidades do povo brasileiro e as condições de desenvolvimento da sociedade de modo que a educação pudesse atendê-las. O fato de Dante ter sido convidado a assumir a DEPE mostra o reconhecimento de sua atuação como pesquisador da área. O convite foi, ainda, ao encontro de sua concepção de pesquisa educacional, que visava, primeiramente, conhecer a realidade brasileira para que soluções adequadas fossem pensadas (Leite, 2008f). Na revista do CRPE, "Pesquisa e Planejamento", Dante publicou três artigos: O brinquedo, a leitura e a criança (Leite, 2008d), Promoção automática e adequação do currículo ao desenvolvimento do aluno (Leite, 2008e), Análise de conteúdo dos livros de leitura da escola primária (1960), além de resenhas de livros internacionais de interesse para a formação de educadores (Mustapha, 2014). Realizou também diversos estudos sobre currículos e livros didáticos na escola primária (Schmidt \& Neves, 2002).

Depois de se desligar do CRPE, trabalhou no Departamento de Pedagogia da Faculdade de Filosofia, Ciências e Letras (FFLC) de Araraquara, onde foi professor de Psicologia e de Psicologia Educacional no curso de Pedagogia de 1959 a 1971. Durante esse período, o interesse pela relação entre Psicologia e Literatura, tema frequente em seus estudos, constantemente ampliado e aprofundado, resultou na tese de livre-docência intitulada Psicologia e Literatura, defendida em 1964, publicada em 1967 (Leite, 2002).

Retornou para São Paulo, em 1971, e se tornou Chefe do Departamento de Psicologia Social e do Trabalho (PST) do IP-USP. Em 1973, tornou-se Professor Titular do PST. Foi diretor do Instituto de Psicologia da USP de 1974 a 1976, ano de sua morte. Relatos de pessoas que conviveram com o intelectual nesse período o retratam como uma pessoa democrática, o que foi marcante na época de repressão política da ditadura militar (1964-1985). Dante era 
comumente visto pelos corredores, avesso a formalidades, conversando de igual para igual com funcionários e alunos, era querido e respeitado intelectualmente (Bosi, 1976; Paiva, 2000; Schmidt \& Neves, 2000). Era contrário ao governo militar e ajudou alunos perseguidos, depondo várias vezes a favor deles, conforme relato de Miriam L. Moreira Leite (Schmidt \& Neves, 2000).

A fim de justificar o que se segue, vale esclarecer que as fontes da pesquisa, quais sejam, as obras de Dante Moreira Leite, artigos e livros dedicados à análise de sua produção científica e intelectual, a documentação disponível no Acervo Dante Moreira Leite e na biblioteca do Instituto de Psicologia da USP, encontram-se detalhadamente apresentadas em Zampronha (2017). Com base nessas fontes, foi possível identificar o fio condutor que percorre a obra do pesquisador - os estudos sobre o preconceito e a ideologia. Ambos os conceitos estão presentes em suas pesquisas desde os primeiros artigos que publicou, em 1950 (Leite, 2008a, 2008b), e em sua tese de doutoramento, defendida em 1954, publicada no Boletim no 230/Psicologia no 7, em 1959 (Leite, 1959). Dante retomou a pesquisa de doutorado, aprofundou e ampliou o estudo, o que resultou em um livro publicado em 1969 (Leite, 1983).

Os mencionados estudos, realizados em diferentes momentos da trajetória do intelectual, analisam não só a sociedade brasileira, por meio de ensaios e de pesquisa empírica, mas, também, a forma como ela é retratada na literatura nacional, com foco nos dois conceitos: preconceito e ideologia. Tais obras são consideradas representativas de sua produção acadêmica e, por isso, foram escolhidas como fonte de pesquisa, as quais, para fins deste artigo, circunscrevem-se à discussão apresentada pelo autor em estudos e pesquisas referentes à educação.

O tratamento dos dados consiste em relacionar a crítica social formulada pelo intelectual, à medida que debate problemas sociais nacionais, com as principais conclusões da teoria crítica da sociedade, visando explorar os potenciais e limites de tal crítica social. A análise acompanha a apresentação das pesquisas selecionadas, visto que diz respeito aos resultados e à discussão elaborada por Dante.

\section{Educação, Formação e Crítica Social}

A organização social determinada pelo sistema econômico capitalista, que se fundamenta, essencialmente, na exploração e na dominação do homem pelo homem - do trabalhador pelo detentor dos meios de produção -, impõe importantes consequências à subjetividade, tal como a reificação da consciência, característica condicional para perpetuação da dominação e da reprodução desse sistema. No polo oposto à reificação, tem-se o esclarecimento como obstáculo à 
manutenção do status quo, na medida em que implica resistência e crítica. Tomando o pensamento de Adorno (2001) como referência, o homem se mantém como um apêndice de máquinas, conforme descrito por Marx no século XIX, à medida que são as necessidades do aparato de produção social que determinam a ação humana em detrimento das necessidades individuais. Esse ordenamento, em que o homem serve ao aparato e não a si próprio, revela o aspecto desumanizador e irracional dessa sociedade.

A lógica do lucro e da produtividade se expandiu para além das relações de produção e o critério de eficiência determinou, também, o desenvolvimento tecnológico e científico. O conhecimento produzido mais valorizado é aquele que tem aplicação prática e imediata e oferece resultados igualmente rápidos (Horkheimer, 1991). O pensamento crítico e especulativo tem sua importância cada vez menos reconhecida. O ensino, por sua vez, desde o nível básico até o superior, tende a reproduzir e a manter as citadas características, formando sujeitos, prioritariamente, para o mercado de trabalho e não para que adquiram a capacidade de criticar as condições a que estão submetidos, marcadas por violência e injustiça, de modo que possam vislumbrar alternativas para a forma como a sociedade está organizada.

Ora, sendo a Psicologia uma ciência que permite analisar e compreender o indivíduo em suas relações sociais, incluindo os mecanismos irracionais, isto é, aqueles que o fazem aderir ao que é contrário a seus interesses e necessidades vitais, tal como descrito acima e, no limite, em casos de sistemas totalitários (Adorno, 2015; Horkheimer \& Adorno, 1973), é pertinente se debruçar sobre o conhecimento produzido pela ciência em questão, procurando identificar como desenvolve a crítica social. Em outras palavras, as pesquisas psicológicas, diante dos resultados encontrados, indicadores de problemas de ordem social, propõem alternativas que limitam-se à adaptação e ao "ajustamento" mecânico à ordem social vigente ou visam fortalecer o indivíduo para resistir e contribuir para a superação das determinações sociais impostas por essa ordem, tendo em vista alcançar novas possibilidades de organização, justa e humana? Sustenta-se, aqui, que a Psicologia tem uma função social e um potencial transformador, à medida que possa contribuir para a crítica ao sistema social existente e para o esclarecimento dos indivíduos. Por isso é essencial que a pesquisa em Psicologia, além de buscar conhecer a realidade, problematize os resultados obtidos, confrontando-os com as determinantes objetivas.

Tomando essas reflexões como ponto de partida, apresenta-se, a seguir, uma síntese dos estudos de Dante Moreira Leite no campo educacional, procurando tensionar as suas considerações com as condições objetivas próprias da sociedade capitalista e brasileira. 


\section{Análises de Dante Moreira Leite acerca da Educação Brasileira}

Destacam-se, neste item, algumas das elaborações de Dante Moreira Leite acerca da Educação, com a intenção de apresentar seu pensamento, sem esgotar o tema, uma vez que a bibliografia a esse respeito é extensa ${ }^{4}$. Parte-se da concepção apresentada pelo autor de que a educação acessível para todos é fundamental para a formação do sujeito do ponto de vista político:

A instrução corresponde também a um ideal político: quando se transferem ao sufrágio universal as decisões políticas, admitese que o eleitor seja capaz de escolher entre diferentes correntes da opinião. Essas condições criam a necessidade de uma escola para todos, e não apenas para um grupo; precisamente por essa razão, a ideia de uma escola para alguns, selecionados por reprovações, passa a ser seriamente discutida (Leite, 2008e, p. 241-242).

O intelectual não se preocupou apenas com a acessibilidade da escola, mas também com a qualidade do ensino que, sustenta, deve ser motivador para a permanência do aluno. Nos anos 1950, o pesquisador refletia sobre problemas na educação brasileira e afirmava que não podem ser solucionados por meio de leis, pois decorrem da ênfase na preparação para exames, da repetência escolar, da organização do currículo e da concepção do ensino com base em prêmios e castigos.

Como sabemos, a estratégia de modificar leis permanece sendo empregada, até hoje, sem solucionar as dificuldades e problemas básicos do ensino (Cury, 2016). Por isso, a crítica de Dante às alterações legais continua válida:

não é um decreto que vai modificar a maneira de estudar, melhorar os livros, ensinar os pais a maneira correta de orientar os filhos, dar vida a uma cultura que é cópia de cultura estranha. Não é um decreto que vai alfabetizar os alunos do primário, ou interessá-los pelo estudo secundário. Pelo contrário: nossa impressão é que a crítica mal informada ao ensino é um dos males da educação nacional (Leite, 2008c, p. 241-242).

Tendo sido também professor em colégios particulares, no que, hoje, corresponde ao Ensino Médio, o pesquisador tinha a percepção tanto de pensador da educação, do ponto de vista da Psicologia, quanto da prática de educador. Uma das questões que o preocupava, como se vê na citação a seguir, era o ensino voltado à preparação para 
exames, sejam as provas do curso ou o vestibular: "Toda a preocupação deve ser finalmente no ensino brasileiro o bendito exame. A abençoada sabatina mensal, a glória suprema do exame vestibular. O vestibular. Espantalho de alunos, fonte de tantos cursinhos para ensinar o que devia ter sido aprendido" (Leite, 2008c, p. 242).

O ensino que enfatiza a memorização em detrimento da imaginação e da criação intelectual é desmotivador para o aluno, além de não implicar, necessariamente, aprendizado. Esse problema não é exclusivo do ensino brasileiro, mas sim da sociedade regida pelo sistema econômico capitalista. Assim Adorno (2011) refere-se às exigências de concurso para professor na Alemanha:

A colcha de retalhos formada de declamação ideológica e de fatos que foram apropriados, isto é, na maior parte das vezes decorados, revela que foi rompido o nexo entre objeto e reflexão. A constatação disso nos exames é recorrente, levando imediatamente a concluir pela ausência de formação cultural (Bildung) necessária a quem pretende ser um formador (Adorno, 2011, p. 63).

Retomando as características imediatistas da sociedade capitalista, que considera o esclarecimento como um obstáculo à sua manutenção e fomenta freneticamente a formação para e pelo trabalho, torna-se evidente o porquê de o ensino priorizar a memorização em detrimento da reflexão. Não é à toa que, no excerto acima, Adorno menciona a declamação ideológica de conteúdos. Interpõe-se, dessa maneira, uma distância entre o aluno e o conhecimento, refletindo a cisão entre sujeito e objeto, inerente à ideologia (Adorno, 2005), de modo que o sujeito não se percebe e não se pensa como parte constituinte da sociedade, e nem mesmo constituído por ela. Uma das graves consequências do não reconhecimento é conformar-se, concebendo a realidade como decorrente de um processo natural e externo de desenvolvimento e não do movimento histórico. Tais críticas remetem, novamente, ao papel político da educação, que não se realiza plenamente na atual sociedade. As consequências desse tipo de ensino e aprendizado constituem um ciclo em que alunos, apesar de pouco ou nada terem aprendido, tornam-se professores. De acordo com Dante:

Não aprenderam? Certamente não; mas seus professores também não, os autores dos livros que lêem sabem as fórmulas que copiam, bem ou mal, de outros livros.

Quando estuda Química ou Física o aluno não é levado para o laboratório para verificar um fenômeno, fazer um experimento. Simplesmente copia a ciência da lousa e resolve depois 
quinhentos problemas artificiais, usando a mesma fórmula (Leite, 2008c, p. 241).

Tão prejudicial quanto a simples memorização, é a reprovação escolar (Leite, 2008e). O intelectual apresenta as desvantagens dessa prática, como o desinteresse do aluno e sua associação a um castigo, pondera também sobre os problemas do ensino orientado por prêmios e castigos. O maior problema identificado é que, dessa maneira, o aprendizado escolar deixa de ser um fim em si e passa a ser um meio para obter a premiação e escapar da punição. Em suas palavras:

Em primeiro lugar, o prêmio e o castigo (sob as várias formas de promoção, aplauso e reprovação) passaram de meios a fins; - aluno não estuda para aprender, mas para evitar a reprovação, ou receber a nota boa. A experiência acumulada parece indicar que o aluno interessado em notas não está, somente por essa razão, qualificado como o que continuará a interessar-se pelo conhecimento. Desaparecido o incentivo, desaparece também o seu esforço. Mais importante que isso, deve-se considerar o caso dos alunos reprovados. Estes com frequência abandonam a escola, não porque não pudessem interessar-se por ela, se fossem outras as condições existentes, mas para evitar as frustrações constantes a que estão submetidos (Leite, 2008e, p. 261-262, grifo do autor).

Quando a educação deixa de ser um fim em si mesma, deixa de ser uma experiência formativa e torna-se apenas um meio para obter determinados resultados, reproduzindo, mais uma vez, a ordenação social. Assim como no trabalho alienado, em que o operário não se reconhece em sua produção (Marx, 2013), o ensino desprovido de sentido torna-se mercadoria de troca. Nesse sentido, sua finalidade é meramente a nota, o diploma, a possibilidade de ingresso no mercado de trabalho, e não a aquisição de conhecimento, o desenvolvimento da autonomia - no sentido kantiano - ou a libertação.

Em relação ao desenvolvimento, fora do Brasil, tanto da psicologia educacional quanto da psicologia da criança, o intelectual afirma que ambas tiveram início como decorrência da industrialização, por isso, tal desenvolvimento está relacionado às mudanças das condições de vida, tais como a deterioração da vida familiar, as consequências do aumento do trabalho - adulto e infantil - nas fábricas, além de fatores ideológicos, como, por exemplo, a necessidade de mão de obra especializada, sustentando que a aplicação de um conhecimento técnico, como a Psicologia, "nunca é independente das ideologias dominantes" (Leite, 2008f, p. 324). Prossegue esclarecendo que, na 
sociedade contemporânea, "o conhecimento técnico é, muitas vezes, posto a serviço das ideologias, transformando-se em seu instrumento" (Leite, 2008f, p. 324). Embora faça essas afirmações, Dante não critica as consequências da relação entre aplicação do conhecimento e ideologia. Provavelmente porque sua concepção de ideologia está relacionada a teorias e ideias que não são cientificamente comprovadas e não com a concepção de ocultação da realidade ${ }^{5}$. Compreende que o avanço científico na área está relacionado à necessidade de atender à demanda de mão de obra, mas não considera que isso altera o objetivo educacional de formação do indivíduo.

Para o pesquisador, a ciência desenvolvida e aplicada no país deve considerar que nem todas as crianças têm infância, visto que muitas trabalham desde pequenas; o índice de mortalidade infantil é alto; crianças chegam subnutridas às escolas, que ainda não estão materialmente equipadas para atender a toda a população. Por essas razões, afirma: "as limitações da Psicologia, no caso da educação brasileira, podem ser compreendidas se pensamos que muitos dos nossos problemas educacionais não chegam ainda a ser psicológicos; são sociais" (Leite, 2008f, p. 350).

Em sua concepção, antes de resolver questões relacionadas ao método de ensino, à adaptação do currículo às fases do desenvolvimento infantil, por exemplo, há problemas mais prementes a serem solucionados. Para Dante, o papel da Psicologia é conhecer a realidade brasileira, identificar seus problemas educacionais, empregando técnicas e instrumentos já obtidos ou criando soluções exigidas especificamente pelos problemas nacionais, sem transpor conhecimento de outras culturas para essa realidade, já que este não é válido e, portanto, é inútil. Sustenta que "a análise psicológica não perde interesse nem se torna extemporânea, mas deve ser compreendida como auxiliar da solução social que se deve encontrar para os nossos problemas educacionais mais urgentes" (Leite, 2008f, p. 351).

Como soluções para esses problemas, propõe algumas alternativas. Primeiramente, sugere a possibilidade de realizar o ensino por meio de processos mais rápidos e econômicos, simplificando-o para melhorar o aproveitamento. A simplificação ocorreria pela eliminação da necessidade de decorar uma série de informações desarticuladas, dando maior tempo para o aprendizado mais eficiente de habilidades básicas que, se não forem bem aprendidas, constituirão obstáculo permanente no desenvolvimento futuro. A segunda alternativa é o conhecimento das fases de desenvolvimento da infância e adolescência, interesses e possibilidades de aprendizagem. Em terceiro lugar, sugere a organização de programas de acordo com as condições materiais das escolas, considerando suas limitações, e ao desenvolvimento do educando e, por fim, propõe introduzir a 
promoção automática. Em suas palavras, são sugestões “modestas e de fácil execução" (Leite, 2008f, p. 342), que não exigem grandes recursos materiais ou humanos. Assim pondera:

Nessas sugestões aparece, provavelmente, um preconceito do autor deste trabalho: a escola existe para receber e manter o maior número possível de alunos. O papel das escolas, na vida social, não é o de preparar escritores, cientistas ou filósofos e por isso a maior capacidade intelectual (ou o que a escola julga que seja capacidade intelectual) não é o único nem o mais importante critério de avaliação, sobretudo nas escolas primárias e de nível médio. O que estas devem fazer é preparar o cidadão e, do ponto de vista individual, permitir o desenvolvimento da personalidade do educando. A escola intelectualista deixa de lado as questões vitais para a criança e o adolescente e, em última análise, estabelece critérios que valem apenas para a própria escola. Nesse processo, a vida intelectual autêntica desaparece - porque sua autenticidade depende de sua adequação para tratar dos problemas humanos, talvez demasiadamente humanos.

Essas afirmações procuram introduzir a ideia de que uma escola secundária mais simples não é, necessariamente, mais fácil ou menos útil. $O$ que tem muito pouco sentido é criar dificuldades artificiais e acrescentá-las às dificuldades que $o$ adolescente inevitavelmente enfrenta no seu processo de ajustamento social (Leite, 2008f, p. 345-346).

No excerto, nota-se que o autor, embora reconheça e critique as dificuldades do ensino brasileiro, procura meios de, diante delas, adaptar o ensino para que ele seja viável. Mostra-se interessando em soluções simples e rápidas para que as crianças e adolescentes tenham acesso à escola e nela permaneçam, o que não é condenável em nenhum aspecto. Porém, com isso, termina defendendo o que aí está, em vez de propor mudanças que permitam o desenvolvimento da vida intelectual autêntica, que ele reconhece faltar no ensino, abrindo mão do compromisso político que ele admite fazer parte da educação, mencionado no início deste item.

A sugestão de eliminar a necessidade da memorização de informações, que acabam não tendo significado para o aluno além da aprovação quando avaliado, é pertinente. Porém, sua preocupação é manter o aluno motivado para o aprendizado, mesmo que para isso o conteúdo seja reduzido - possibilidade que o pesquisador aceita, desde que o conteúdo ensinado seja efetivamente aprendido. Vê-se que mantém a intenção de garantir a formação, incluindo a apropriação e reflexão acerca do que se aprende. Entretanto, o que propõe é uma forma de contornar um problema, sem solucioná-lo; 
além do que, esquece a questão fundamental da formação do futuro professor - se aprende menos, o que ensinará? E como será possível melhorar a educação desse ponto, em que se aprende menos, em diante?

O pesquisador analisou também a, então, crescente importância do brinquedo e da leitura, principalmente na vida de crianças da cidade, que, em geral, não precisavam trabalhar ou assumir responsabilidades atribuídas, desde cedo, às crianças da vida rural. Estudos educacionais da época investigavam se o brinquedo e a leitura considerados agressivos exerciam influência sobre 0 comportamento da criança, podendo levar à delinquência (Bosi, 1976; Rosemberg, 1976). Para Dante, essas brincadeiras têm efeito terapêutico, na medida em que permitem o contato e elaboração de sentimentos agressivos, e não são efeito determinante de agressividade. Considera que "o problema mais sério é apresentado pelas crianças abandonadas - e precisamente porque estas não recebem o afeto e a segurança que podem ser dados pela família" (Leite, 2008c, p. 250). Portanto, é mais provável que crianças e adolescentes de famílias "desorganizadas" (Leite, 2008c, p. 250) tornem-se desajustados socialmente, já que "sua história não é de crianças que tenham tido brinquedos armados ou tenham lido histórias condenáveis; é, com muita frequência, a de crianças sem brinquedos que nunca passaram por uma escola" (Leite, 2008d, p. 250, grifo do autor).

Para o pesquisador, então, o comportamento é consequência do ambiente e da interação social e é tarefa essencial atender essas crianças, que podem vir a se tornar um problema social. O intelectual critica a falha da sociedade em lhes oferecer educação e supõe que os custos para a repressão e o sustento dos desajustados sejam maiores do que os que são investidos na educação.

Se o início da civilização industrial desorganiza a família tradicional e as formas tradicionais de proteção à infância (como o apadrinhamento), precisa criar instituições que as substituam.

Compreende-se, assim, que a escola deixe de ser uma instituição voltada, exclusivamente, para o preparo intelectual, e passe a desempenhar a função muito mais ampla de ajustar a criança à vida social (Leite, 2008d, p. 250-251).

Nessa análise, Dante situa socialmente o problema do brinquedo e da leitura e identifica outros fatores que podem ser mais determinantes no comportamento da criança, ponderando as consequências que isso possa ter na sociedade. A concepção que apresenta em relação ao papel da família, quando afirma que um meio familiar desorganizado apresenta maior probabilidade de criar um desajustado, sem incluir a 
condição social na análise, remete a valores conservadores. O pesquisador parece se referir apenas à desorganização familiar em situação de pobreza ao mencionar falta de brinquedos e o fato de a criança não frequentar a escola, excluindo, dessa maneira, famílias possivelmente desorganizadas com uma condição social diferente.

Destaca-se também a mencionada função escolar de promover o ajustamento da criança à vida social, referida pelo pesquisador ao longo do texto e em outras publicações. É importante mencionar que termos como "ajuste" e "ajustar" eram comuns para se referir à função da profissão de psicólogo, sendo utilizados, por exemplo, na justificativa, escrita por Dante, que acompanhou Substitutivo ao Projeto de Lei no 3825-A ${ }^{6}$ (Instituto de Psicologia da Pontifícia Universidade Católica de São Paulo [IPPUC-SP], 1958). Entende-se que o autor fez uso da linguagem corrente, entretanto, como os conceitos são precisos e não são inocentes, parece-nos pertinente retomar as considerações de Adorno (2011) a respeito do conceito de adaptação: a educação deve promover um tanto de adaptação, visto que uma de suas funções é preparar os homens para viverem na realidade, mas, sua finalidade primordial é promover a conscientização, a resistência ao que adapta e a emancipação:

A educação seria impotente e ideológica se ignorasse o objetivo da adaptação e não preparasse os homens para se orientarem no mundo. Porém ela seria igualmente questionável se ficasse nisto, produzindo nada além de well adjusted people, pessoas bem ajustadas, em consequência do que a situação existente se impõe precisamente no que tem de pior (Adorno, 2011, p. 143, grifos do autor).

A necessidade de certo nível de adaptação não significa que, para o indivíduo, adaptar-se seja algo simples. Conforme Adorno (2011), a realidade se impõe no que tem de pior, fazendo com que os sujeitos imponham a adaptação a si mesmos por meio de um processo doloroso. Portanto, existe a necessidade de ajuste - ou adaptação às condições sociais ao mesmo tempo que o puro ajuste significa cisão entre sujeito e sociedade, alienação, fator que impede a crítica e a resistência, logo, a transformação.

\section{Conceitos morais em seis livros didáticos primários brasileiros e Preconceito e patriotismo em seis livros didáticos primários brasileiros - 1950}

Este item destaca os dois artigos publicados por Dante Moreira Leite em 1950. Tais estudos são significativos porque marcam o início de sua trajetória como pesquisador do campo educacional e constituem 
a base do que desenvolverá posteriormente nas pesquisas acerca do caráter nacional brasileiro. Segundo Jorge Nagle (1976), são as pesquisas mais importantes de sua produção acadêmica pelo fato de debaterem o conteúdo das obras didáticas e por suscitarem debates no campo da literatura e do desenvolvimento infantil. Para Ecléa Bosi (1976), essas publicações são fundamentais porque constituem o núcleo da sua atividade de pesquisador sobre os preconceitos, tema que desenvolverá, posteriormente, com os estudos sobre o caráter nacional.

No primeiro artigo, o autor constata, com base na análise das lições contidas em seis livros didáticos infantis, que valores morais, ideias preconceituosas e patriotismo são transmitidos por meio das histórias, o que chama sua atenção, e, por isso, realiza um segundo estudo com ênfase nos temas: preconceito e patriotismo.

$\mathrm{O}$ estudo de conceitos morais, de acordo com o pesquisador, cabe tanto à Psicologia quanto à Sociologia, porém, há limites e distinções entre as a análises realizadas pelas duas ciências. Trata-se de:

um estudo sociológico, se examinamos esses conceitos no seu aspecto social e nas variações ou uniformidades de tempo e lugar.

Mas os conceitos morais têm também um outro aspecto, psicológico, que é o da sua aceitação ou rejeição pelos indivíduos, o da sua prática ou simples aceitação verbal (Leite, 2008a, p. 171).

Quanto ao aspecto psicológico, que inclui a aceitação ou rejeição dos valores morais, bem como a prática por meio de atitudes ou condutas, considera que pode haver diferença entre a aceitação abstrata e a atividade concreta, fazendo com que os sujeitos aceitem os valores, mas não ajam de acordo com eles. Entende que o estudo psicológico pressupõe o sociológico, já que a aceitação ou rejeição individual refere-se a valores de ordem social; entretanto, ressalta que essa separação acontece apenas no campo de investigação, ou seja, não se trata de duas naturezas distintas (Leite, 2008a).

Dante parte da premissa de que o material didático aprovado e adotado pelas instituições de ensino "apresentam os valores morais que uma sociedade ou um grupo social pretendem transmitir pela educação" (Leite, 2008a, p. 172). Daí a hipótese de que há intenção moralizadora e a realidade apresentada nos livros é deformada e ajustada aos conceitos morais almejados. Para ele, o preconceito e suas manifestações, como o etnocentrismo, o nacionalismo e o racismo, são distorções da realidade que podem conduzir a comportamentos preconceituosos e a efeitos graves, dependendo da forma e intensidade com que são expressados. 
A fonte de sua pesquisa foi composta por seis livros didáticos infantis, escritos por autores brasileiros, para escolas brasileiras, compreendidos em um período de aproximadamente cinquenta anos, de 1890 a 1940 (Leite, 2008a). O método de pesquisa, no caso da pesquisa sobre conceitos morais, consistiu em analisar se as histórias das lições são moralmente neutras ou têm intenção moralizadora, identificar e catalogar os conceitos morais, que são denominados de "virtudes" quando se referem a comportamentos valorizados, considerados positivos, e de "erros condenados" quando remetem a comportamentos considerados negativos (Leite, 2008a). No estudo sobre preconceito e patriotismo, o pesquisador discute a forma como tais conceitos são apresentados nas lições.

Ao investigar valores morais presentes nas histórias, o pesquisador não identifica uniformidade nos conceitos ensinados, visto que são variados e se repetem poucas vezes. As virtudes mais frequentes são o Patriotismo (aparece em um total de 26 vezes nos livros), seguido do Trabalho (aparece 24 vezes), da Caridade (15 vezes) e do Estudo (13 vezes). As demais aparecem menos de 10 vezes. $O$ pesquisador faz uma análise geral dos dados, com foco sobre a verificação da hipótese quanto ao falseamento da realidade, sem se deter em cada um dos conceitos morais. No entanto, alguns dados chamam a atenção, por isso são destacados a seguir.

O fato de a virtude Trabalho aparecer 24 vezes, sendo a segunda mais frequente nas lições, parece significativo. A virtude Bondade aparece 3 vezes, Honra, 1 vez e Amizade, 1 vez, revelando que são valores preteridos, o que é típico da sociedade capitalista, que fomenta individualismo e competição em vez de solidariedade, em que a preocupação maior é garantir a própria sobrevivência (Adorno, 2011). Virtudes como Heroísmo, que aparece 6 vezes, Obediência, também 6 vezes e Tenacidade, 5 vezes, são mais frequentes do que Justiça, que aparece 4 vezes, Paz, 2 vezes e Liberdade, 2 vezes. Nota-se que as histórias reproduzem o clima social, em que a obediência é mais valorizada do que a liberdade, já que os indivíduos devem ser controlados e se adaptar às condições vigentes, para que sejam perpetuadas, de modo que "aqueles que sofrem pela pressão social podem, frequentemente, tender a transferir essa pressão para cima de outros, em vez de dar as mãos a quem é seu companheiro na situação de vítima" 7 (Adorno, Frenkel-Brunswik, Levinson, \& Sanford, 1969, p. 612, tradução livre).

Leite (2008a) identifica valores que indicam atitudes em relação à pobreza que também merecem ser destacadas. Orgulho da pobreza (aparece $1 \mathrm{vez}$ ), Alegrar o pobre ( $1 \mathrm{vez}$ ), Proteção ao pobre (1 vez). No levantamento de erros condenados, Preconceito contra a pobreza aparece uma vez. Nota-se uma atitude de condescendência, que o pesquisador destaca em relação ao negro, no segundo artigo, como será detalhado adiante. É mais um tipo de conceito que endossa a 
realidade: não se pensa em erradicar a pobreza, mas, sim, torná-la motivo de orgulho, alegrando e protegendo o sujeito que se encontra nessa situação, naturalizada e persistente.

Os erros condenados, que têm frequência muito menor que as virtudes nas lições, também foram identificados e classificados. Os mais encontrados são: a ambição, o cigarro, a vingança, o preconceito de raça e a escravidão, sendo que cada um deles aparece duas vezes no total das histórias.

O autor conclui que a aceitação acrítica de valores morais tem graves consequências para os educandos, como o choque quando descobrem o mundo real, que Ihes era omitido até então. O conflito maior, contudo, está na comunicação dos valores em fórmulas prontas, que indicam os comportamentos esperados (valorizados e condenáveis), sem reflexão. Constata que os livros, além de mostrarem uma realidade falsa, omitem determinados temas já presentes na infância, tais como a sexualidade, bem como "a perseguição do mais fraco pelo mais forte" (Leite, 2008a, p. 205). O intelectual sustenta que a omissão desses temas é significativa, pois deforma a realidade que faz parte da vida das crianças. Essa omissão implica, no entanto, algo mais profundo: deixa de discutir temas essenciais para a formação, que são igualmente fundamentais para a sociedade. Uma das características da sociedade industrial é a frieza frente ao sofrimento, à fragilidade e à miséria do outro, decorrente da pressão que a civilização impõe e do fato de as pessoas tenderem a amar mais objetos tecnológicos do que umas às outras. A frieza leva à indiferença em relação ao que acontece com os demais. Essa configuração é bastante perigosa, uma vez que abre caminho para o preconceito e para a repetição da barbárie. Considerando que o caráter já está em formação na primeira infância, esse é um momento precioso para que, por meio da educação, esses mecanismos sejam esclarecidos e para que se promova a solidariedade (Adorno, 2011). A omissão da perseguição do mais fraco pelo mais forte pode naturalizar tal relação, à medida que se deixa de discuti-la. De acordo com Horkheimer, "a crença de que sempre deve haver um superior e um inferior e que obediência é uma necessidade, constitui um dos mais importantes fatores culturais nas forças dinâmicas que moldam a sociedade" ${ }^{8}$ (1936, p. 900, tradução livre). Nesse caso também se perde a oportunidade de discutir e incentivar a cooperação.

A virtude Patriotismo é a mais frequente dentre as identificadas pelo pesquisador. Dos 6 livros, 4 apresentam o Patriotismo como conceito moral, perfazendo um total de 26 lições. Dante relaciona a noção de superioridade do próprio país, presente no patriotismo, a uma forma de preconceito, "em que os hábitos de outros povos, porque diferentes, são encarados como piores ou errados" (Leite, 2008b, p. 212), o que, por sua vez, pode conduzir ao nacionalismo e ao 
racismo. Por isso, realizou a segunda pesquisa, em que analisa mais detalhadamente esses dois conceitos. Desse estudo, conclui que a realidade das histórias é deformada e apresentada apenas como positiva; o preconceito é mostrado de forma naturalizada e corriqueira, ou seja, não se define o conceito para os leitores, mas ele está presente nos textos; o patriotismo é observado por meio da valorização de símbolos nacionais, ou da descrição da grandeza do Brasil, sendo que algumas lições apenas se referem à pátria como algo grandioso, que deve ser amado e valorizado. A tentativa de incutir valores, nos leitores, dessa forma difusa, remete ao discurso do agitador, tema analisado nos Estudos sobre preconceito ${ }^{9}$. Após a análise de alguns discursos, os pesquisadores observaram que os agitadores incitam o ódio inflamadamente sem justificativa lógica, apelam para clichês e estereótipos mediante falas vazias (Lowenthal \& Guterman, 1949). O ensino escolar, com as características aqui descritas, forma sujeitos facilmente capturados por esse tipo de propaganda. Conforme descrevem Horkheimer e Adorno (1973) ao se referirem ao estudo Prophets of deceit (Profetas da enganação) "os instrumentos de propaganda do tipo nazista são rígidos estereótipos de pensamentos e repetições constantes. Com esses meios, as reações vão sendo gradualmente embotadas (...) e as resistências da consciência são minadas (Horkheimer \& Adorno, 1973, p. 174).

O ensino que exerce função ideológica leva à adaptação irrefletida à realidade e à pressão social, bem como à indiferença e hostilidade em relação ao outro. Essa configuração enfraquece o sujeito, favorece o preconceito e a adesão à propaganda, condições que não só mantêm a realidade como favorecem a instalação de sistemas totalitários.

\section{Considerações finais}

Dante foi um pesquisador rigoroso e sistemático, com amplas leituras, que abrangiam o conhecimento de outras áreas, que empregava para situar seus problemas de pesquisa. Apesar de assim proceder, considerando a importância dos fatores históricos e sociais em seus estudos, ele o faz para compreender o desenvolvimento histórico de seu objeto sem empregar tais conhecimentos nas conclusões ou desdobramentos dos resultados no âmbito social. Quando discute os problemas educacionais brasileiros, critica a forma como a sociedade organiza a educação e propõe alternativas para viabilizar o ensino sob as condições vigentes.

O fato de separar a pesquisa psicológica da sociológica, mesmo que apenas didaticamente, limita a análise. É essa delimitação que faz com que, ao analisar os problemas identificados, explique-os pela Psicologia e pondere suas consequências no âmbito da psique individual, sem incluir implicações sociais. Preocupou-se, 
evidentemente, com a formação das crianças, mas tendo como foco as consequências psicológicas para o aluno. Por exemplo, o livro didático, que deveria ser um instrumento esclarecedor, se torna um divulgador de ideologia e preconceito, fato que tem desdobramentos em toda a sociedade, mas o autor deixa esse aspecto a cargo da Sociologia.

Vale lembrar que os livros didáticos analisados foram escritos numa época em que o pensamento era influenciado por teorias racistas que, por meio de diversas explicações, justificavam diferenças sociais e econômicas, falseavam a realidade e naturalizavam 0 desenvolvimento histórico e social. Dante elabora uma explicação para a existência de teorias racistas, afirmando que muitas são tentativas de explicação do fenômeno social, baseadas mais em crenças e valores do que em verificações empíricas, fundamentadas na ciência (Leite, 2008b). De modo semelhante, o preconceito também "é contraditório ou fundado em razões extra fenomenais, visto que, mesmo que assuma uma forma lógica, é infundado" (Leite, 2008b, p. 211). Reitera-se, aqui, a crença de Dante na resolução dos problemas sociais conforme o avanço das ciências, omitindo o fato de que as ciências - incluindo, a Psicologia, a Biologia e a Estatística, entre outras - prestaram-se à formulação daquelas teorias, quando se encontravam em fases significativamente mais desenvolvidas do que em fases iniciais.

Do mesmo modo, o próprio Dante é marcado pelas determinações objetivas de seu tempo. A Psicologia, especialmente a Psicologia Social, se torna crítica algumas décadas depois, superando os limites entre pesquisas psicológicas e sociológicas. Isso acontece quando os psicólogos passam ser influenciados pelo pensamento marxista, da escola de Frankfurt, da Psicologia da Libertação, da Psicologia Política. Hoje, está muito mais consolidada a noção de que a psicologia pode recorrer a outros campos do saber para produzir conhecimento em relação ao sujeito e à sociedade sem perder de vista seu objeto de estudo, que é o sujeito, e sem retirá-lo da totalidade em que vive. Em outras palavras, sem deixar de ser Psicologia e sem "psicologizar" todos os fenômenos.

O intelectual deixou uma extensa e importante bibliografia. Sugere-se que mais pesquisas sobre sua obra sejam realizadas. Um vasto corpus documental foi consultado para realizar este estudo, mas nem tudo pode ser utilizado e diversos resultados interessantes não puderam ser incluídos. Vale a pena, portanto, dar continuidade ao estudo. Por fim, a realização desta pesquisa possibilitou conhecer mais da obra de um intelectual importante para a Psicologia e a cultura, que não deveria ser esquecido, principalmente, na área científica a que se dedicou. Espera-se que este estudo tenha feito jus à memória de Dante Moreira Leite e contribua para a reflexão acerca do papel da Psicologia na crítica à sociedade. 


\section{Referências}

Adorno, T. W., Frenkel-Brunswik, E., Levinson, D. J., \& Sanford, R. N. (1969). The authoritarian personality. New York: The Norton Library.

Adorno, T. W. (2001). Late Capitalism or Industrial Society? (Opening Address to the 16th German Sociological Congress, D. Redmond, Trad.). (Original publicado em 1968). Recuperado de http://members. efn.org/ dredmond/AdornoSozAddr.PDF. Acesso em 13/06/2017.

Adorno, T. W. (2005). Critical Models: Interventions and Catchwords (H. W. Pickford, Trad.). Nova York: Columbia University Press.

Adorno, T. W. (2011). Educação e emancipação (W. L. Maar, Trad.). São Paulo: Paz e terra. (Obra original publicada em 1971)

Adorno, T. W. (2015). A psicanálise revisada. In T. W. Adorno, Ensaios sobre psicologia geral e psicanálise (V. Freitas, Trad.). São Paulo: Editora UNESP. (Obra original publicada em 1952)

Baran, P. A. (1961). The Commitment of the Intellectual. Monthly Review: an independent socialist magazine. New York, 13(1). Recuperado em 01 de março de 2019, de http://monthlyreview.org/1961/05/01/the-commitment-of-theintellectual/

Bosi, E. (1976). Dante Moreira Leite. Cadernos de Pesquisa. Revista de estudos e pesquisas em educação, (17), 33-36.

Cury, C. R. J. (2016). Vinte Anos da Lei de Diretrizes e Bases da Educação Nacional (LDBEN). Jornal de Políticas Educacionais, 10(20), 3-17.

Horkheimer, M. (1936). Vorwort. In Studien über Autorität und Familie (pp. 900). Springe: Dietrich zu Klampen Verlag.

Horkheimer, M. (1969). Foreword to studies in prejudice. In T. W. Adorno, T. W., E. Frenkel-Brunswik, D. J. Levinson, \& N. Sanford, The Authoritarian Personality (pp. 5-12). New York: The Norton Library.

Horkheimer, M. (1991). Teoria tradicional e teoria crítica. In M. Horkheimer, \& T. W. Adorno, Textos escolhidos (5a ed., Z. Loparic, trad., pp 117-154). São Paulo: Nova Cultural.

Horkheimer, M., \& Adorno, T. W. (1973). Temas básicos da sociologia (A. Cabral, Trad.). São Paulo: Cultrix. (Obra originalmente publicada em 1956)

Instituto de Psicologia da Pontifícia Universidade Católica de São Paulo [IPPUC-SP]. (1958). Crônicas e documentações: Substitutivo apresentado pela Associação Brasileira de Psicólogos e pela Sociedade de Psicologia de São Paulo ao Anteprojeto de Lei $n^{\circ} 3.825 / 1958$, do Ministério da Educação e Cultura. Revista de Psicologia Normal e Patológica, 4(3-4), 394401. 
Leite, D. M. (1959). Caráter nacional brasileiro: descrição das características psicológicas através de ideologias e estereótipos (Tese de Doutorado). Faculdade de Filosofia, Ciências e Letras da Universidade de São Paulo, São Paulo, SP.

Leite, D. M. (1973). Memorial para o concurso de Professor Titular. São Paulo: Universidade de São Paulo, Instituto de Psicologia.

Leite, D. M. (1983) O caráter nacional brasileiro: história de uma ideologia (4a ed.). São Paulo: Livraria Pioneira.

Leite, D. M. (2002). Psicologia e literatura (5a ed. rev.). São Paulo: Editora UNESP.

Leite, D. M. (2008a). Conceitos morais em seis livros didáticos primários brasileiros. In R. M. Leite (Org.), Psicologia diferencial e Estudos em educação (pp. 171-207). São Paulo: Editora UNESP.

Leite, D. M. (2008b). Preconceito racial e patriotismo em seis livros didáticos primários brasileiros. In R. M. Leite (Org.), Psicologia diferencial e Estudos em educação (pp. 209-237). São Paulo: Editora UNESP.

Leite, D. M. (2008c). A situação do ensino no Brasil. In R. M. Leite (Org.), Psicologia diferencial e Estudos em educação (pp. 239243). São Paulo: Editora UNESP.

Leite, D. M. (2008d). O brinquedo, a leitura e a criança. In R. M. Leite (Org.), Psicologia diferencial e estudos em educação (pp. 245251). São Paulo: Editora UNESP.

Leite, D. M. (2008e). Promoção automática e adequação do currículo ao desenvolvimento do aluno. In R. M. Leite (Org.), Psicologia diferencial e estudos em educação (pp. 253-273). São Paulo: Editora UNESP.

Leite, D. M. (2008f). A investigação psicológica em face da educação brasileira. In R. M. Leite (Org.), Psicologia diferencial e estudo em educação (pp. 321-351). São Paulo: Editora UNESP.

Lowenthal, L., \& Guterman, N. (1949). Prophets of Deceit, Studies in Prejudice Series (Vol. 5). Nova York: Harper \& Brothers.

Marx, K. (2013). O capital: crítica da economia política: Livro 1: O processo de produção do capital (R. Enderle, Trad.). São Paulo: Boitempo. (Obra originalmente publicada em 1867)

Mustapha, S. A. dos S. (2014). Trajetória e atuação dos intelectuais e técnicos nas Divisões de Pesquisa do Centro Regional de Pesquisas Educacionais de São Paulo em sua primeira fase (1956-1961) (Dissertação de mestrado). Pontifícia Universidade Católica de São Paulo, SP.

Nagle, J. (1976) A reflexão pedagógica crítica: uma necessidade e um exemplo. Cadernos de Pesquisa, (17), 13-26.

Paiva, G. J. (2000). Dante Moreira Leite: um pioneiro da psicologia social no Brasil. Psicologia USP, São Paulo, 11(2), 25-57. 
Rosemberg, F. (1976). Um psicólogo na literatura infantil. Cadernos de Pesquisa. Revista de estudos e pesquisas em educação, (17), 5-7.

Schmidt, M. L. S., \& Neves, T. F. S. (2002). Dante Moreira Leite. (Coleção Pioneiros da Psicologia Brasileira). Rio de Janeiro: Imago Editora; Brasília, DF: CFP.

Schmidt, M. L. S., \& Neves, T. F. S. (2000). Dante Moreira Leite: ciência psicológica, interdisciplinaridade e diferença. Psicologia USP, 11(2), 59-88.

Zampronha, M. A. G. (2017). Psicologia Social e educação no Brasil: os estudos de Dante Moreira Leite sobre ideologia e preconceito (Tese de Doutorado). Pontifícia Universidade Católica de São Paulo, São Paulo, SP. Recuperado de https://tede2. pucsp. br/handle/handle/20365\#preview-link0

\section{Endereço para correspondência Maria Amélia Güllnitz Zampronha}

Rua 235, s/n - Setor Universitário, CEP 74605-050, Goiânia - GO, Brasil

Endereço eletrônico: ameliagullnitz@gmail.com

Odair Sass

Rua Ministro Godói, 969, 4ํ andar, sala 4E-19, Perdizes, CEP 05015-901, São Paulo - SP, Brasil

Endereço eletrônico: odairsass@pucsp.br

Recebido em: 24/11/2018

Reformulado em: 11/02/2019

Aceito em: 28/02/2019

\section{Notas}

* Psicóloga, doutora em Educação: História, Política, Sociedade, pela PUC-SP, bolsista CNPq. Pós-doutoranda em Educação na UFG, bolsista CAPES-FAPEG.

** Psicólogo, doutor em Psicologia Social. Docente da PUC-SP.

${ }^{1}$ Em seu Memorial para o concurso de Professor Titular (Leite, 1973, p. 5-8), Dante destaca os temas que estudou: estudos sobre literatura infantil, psicologia e literatura, personalidade e cultura - o caráter nacional brasileiro -, percepção social e relações interpessoais, o desenvolvimento da criança, pressão social e compromisso.

${ }^{2}$ A FFCL era um dos Institutos I solados de Ensino Superior do Estado de São Paulo que, em 1976, foram integrados formando a Universidade Estadual Paulista J úlio de Mesquita Filho (Unesp).

${ }^{3} \mathrm{O}$ trabalho de tradução foi realizado junto com sua esposa, Miriam Lifchitz Moreira Leite. A colaboração de Miriam como tradutora consta em 6 das 49 obras traduzidas, entretanto, não é possível precisar se colaborou com mais traduções.

${ }^{4}$ Para uma descrição mais detalhada dos principais textos educacionais de Dante Moreira Leite, recomenda-se a leitura do artigo de Jorge Nagle (1976).

${ }^{5}$ A discussão acerca da compreensão do intelectual quanto ao conceito de ideologia e da forma como o emprega em suas obras é aprofundada em Zampronha (2017).

6 A participação do pesquisador na regulamentação da profissão de psicólogo é apresentada com mais detalhes por Zampronha (2017). 
7 “... those who suffer from social pressure may frequently tend to transfer this pressure onto others rather than to join hands with their fellow victims" (Adorno, et al., 1969, p. 612).

8 “... the belief that there must always be a superior and an inferior and that obedience is a necessity, constitutes one of the most important cultural factor in the dynamic forces that shape society" (Horkheimer, 1936, p. 900).

${ }^{9}$ Trata-se do conjunto de cinco volumes publicados em 1949 e 1950, nos Estados Unidos, intitulado Studies in Prejudice, dirigidos por Max Horkheimer e Samuel H. Flowerman, financiados por The Amercian Jewish Commitee.

Financiamento: CNPq e DAAD.

Este artigo de revista Estudos e Pesquisas em Psicologia é licenciado sob uma Licença Creative Commons Atribuição-Não Comercial 3.0 Não Adaptada. 